\title{
LA RELACION INFANCIA Y FAMILIA EN ESPAÑA
}

"On se perd toujours dans l'enfance: les métbodes d'education, le rapport parents-entants, l'enseignement, etc., tout cela donne un moi, mais un moi perdu.»

Jean Paul Sartre

Julio Iglesias de Ussel

El objetivo de este trabajo es examinar - con carácter exploratorio en ocasiones y con los escasos datos disponibles- un aspecto de las relaciones infancia-familia, al que se le ha prestado hata el momento poca atención en España. Me refiero a los efectos de los hijos en algunos aspectos de la relación matrimonial.

No se trata, por consiguiente, de pasar revista a todas las dimensiones de la infancia en la vida familiar. Ni tampoco de emprender una loa a la paternidad y maternidad. Todo lo contrario. El examen de las relaciones hijos-relación matrimonial parte de una óptica deliberadamente crítica o, si se prefiere, negativa. Es decir, intento detectar y desvelar las consecuencias perjudiciales para la dinámica de la relación entre la pareja que introducen los hijos. Invito pues desde ya a dejar al margen cualquier etiqueta de pesimista con que se me quiera adornar. Soy naturalmente consciente que se trata de un enfoque parcial. Pero con un rango peculiar: se trata de una parcialidad deliberada, y exigida por el alcance de un artículo. Tengo que decir en mi descargo, que hay además mucha parcialidad de signo contrario. Abundante literatura laudatoria sobre la infancia que, de forma nada deliberada, ignora el aspecto complementario: las consecuencias negativas de los hijos en la vida familiar, que es el reverso de la moneda.

\section{Rếs}


Tengo que matizar igualmente que me refiero aquí a la familia como unidad de convivencia legalmente vinculada. En ella, desde luego, nacen la mayoría de los niños, cada año, en nuestra sociedad. Se trata, por consiguiente, de la más común; aunque otras formas de convivencia sean hoy más frecuentes que antaño, no las contemplo. Si bien tampoco excluyo que muchas afirmaciones les sean también de aplicación. Otra limitación importante es que en pocos casos he podido precisar mis referencias según clase social y, lo que no es menos importante, dimensión de la familia y rango ocupado por los hijos según sexo. La ausencia de investigaciones previas en España me lo impide.

Un aspecto - sólo en apariencia - sorprendente de los estudios sobre la infancia y la vida familiar es la reducida atención que se presta a la figura del padre. Digo sólo aparentemente por cuanto la infancia ha sido siempre cometido asignado exclusivamente a la mujer. De ahí que el sexismo en la división de tareas se prolongue también a la hora de su análisis. Así, la mayoría de las investigaciones sobre separación y privación de cuidados en la infancia se fijan en las relaciones madre-hijo, y para nada estudian el papel del padre. Se da por excluido que ha de quedar alejado de la crianza y cuidados, por ser materia que no le concierne. Esta tendencia a ignorar la influencia del padre alcanzó su cenit - y al mismo tiempo desarrollo decisivo- con la publicación en 1951 de la obra de Bowlby Los cuidados maternos y la salud mental, donde llegaba a la conclusión que una larga privación de los cuidados maternos tiene sobre el carácter del niño pequeño efectos graves y duraderos. En consecuencia, resulta básico su crianza familiar y los cuidados maternos, reputando como perjudiciales los efectos de jardines de infancia, guarderías e instituciones semejantes. Por supuesto, la obra de Bowlby dio lugar a prolongadas controversias y a una oportuna puntualización de J. Mitchell mostrando su coincidencia temporal con las presiones para el retorno al hogar de la mujer tras la guerra mundial ${ }^{1}$.

Pero ¿y la privación de cuidados y atenciones por parte del padre? Se acepta como hecho incuestionable, sin necesidad de plantearse sus efectos. Se postula tan sólo la disponibilidad absoluta de la madre para el hijo. Mientras tanto los varones quedan en un segundo plano, sin duda frustrando las

La edición castellana de la obra de J. BowlBy, Los cuidados maternos y la salud mental, fue editada por la Organización Mundial de la Salud, Washington, 1954. Una década después la misma institución patrocinó la revisión crítica de las investigaciones realizadas sobre privación materna a cargo, entre otros, de M. Mead, Wootton, Lebovici, Ainsworth; véase Privación de los cuidados maternos. Revisión de sus consecuencias, O.M.S., Ginebra, 1963; sobre J. MrtchelL, Psicoanálisis y feminismo, Barcelona, ed. Anagrama, 1976.

Para España véase el análisis de las consecuencias diferenciales de la privación de padre o madre, en la primera infancia o adolescencia, con datos sobre cuatro mil reclutas de 1965, de M. Martín Serrano, "Huérfano en España", Boletin Documentación del F.I.E.S., vol. 7. ${ }^{\circ}$, núm. 3, 1975, pp. 460-496; en algunos aspectos dicha privación tiene efectos marginales comparando con la incidencia de la clase social. 
gratificaciones de una nueva experiencia de sensibilidad en la relación padrehijo. Esto es, por otra parte, lo más llamativo de una película tan exitosa como Kramer versus Kramer. No radica en el divorcio de los protagonistas, sino en el descubrimiento de la paternidad y las recompensas emocionales que dicho acontecimiento propicia, en un padre hasta entonces afectivamente de espaldas a su hijo. A este respecto convendría también recordar que un hecho tan censurado habitualmente como el trabajo extradoméstico de la mujer, incrementa las relaciones padre-hijo ${ }^{2}$.

En España tampoco parece que haya suscitado excesiva preocupación la escasa intervención del padre en la crianza infantil. Más bien lo contrario. Piénsese, por ejemplo, en el fomento de la emigración exterior, en buena parte de varones casados exclusivamente, $y$ en las secuelas de costos familiares que ha debido comportar. Pero además las menores tasas de incorporación de mujeres casadas a la población activa, el peso de las ideologías tradicionales sobre la distribución de tareas en el hogar, la socialización diferencial por sexo orientando a la mujer hacia la vida doméstica, han configurado el cuidado de los hijos, por lo menos mientras son pequeños, como responsabilidad exclusiva de la mujer. Salvando la limitación geográfica y de clase que contiene, entiendo que esta descripción resulta todavía válida; pese a su extensión la recogeré, pues detalla muy certeramente los mecanismos de exclusión del varón: «Los hombres de clase baja, para compensar una identificación masculina frágil, para alcanzar una reputación de macho entre sus compañeros, deben evitar todo contacto con el mundo privado que sea como 'femenino'. Esta evitación ética significa que el padre-marido debe evitar el contacto frecuente con la casa, y consecuentemente con los niños de ambos sexos, quedando como una figura evanescente en la sombra. No queremos decir que los padres de la clase trabajadora sean emocionalmente indiferentes con sus hijos, o que sean malos padres; sino todo lo contrario. Son hombres sentimentales y orgullosos de su familia. Sin embargo, es también cierto que los mitos y las obligaciones del 'machismo' les obligan a permanecer físicamente distantes y separados de las rutinas diarias de la casa. Así, en la clase baja, el patrón de dominación doméstica femenino y la responsabilidad durante la infancia son asegurados por una especie de negligencia masculina; y continúan minando la formación de identidades masculinas sólidas en las generaciones siguientes. La ausencia del padre en la casa, decretada por las normas sociales del machismo andaluz, incrementa más adelante las dificultades del hijo en sus intentos para desidentificarse de la madre todopoderosa. Y, así, el ciclo continúa» ${ }^{3}$.

${ }^{2}$ Esta influencia de la actividad profesional de la mujer puede verificarse en A. Micher, Activité professionnelle de la femme et vie conjugale. Paris, ed. CNRS, 1974, en especial capítulos $20^{\circ}$ y $30^{\circ}$

${ }^{3}$ Gilmore, D. D., y Gilmore, M. M., "Sobre los machos y los matriarcados: el mito machista en Andalucia", Ethnica (Barcelona), núm. 14, 1978, p. 158. 
Otros muchos aspectos de nuestra vida colectiva - prolongada duración de la jornada de trabajo, pluriempleo, horas extraordinarias, reducida implantación del horario continuado en el trabajo, tiempo empleado en desplazamientos, etc.- impulsan también la desvinculación del padre con los hijos. En cualquier caso, es muy inferior al de la madre el tiempo que cotidianamente pasan en contacto con sus hijos. Las respuestas de niños de 12 años son bien elocuentes ${ }^{4}$ :

Horas pasadas con padres

(niños de 12 años)

\begin{tabular}{|c|c|c|}
\hline & Con padre & Con madre \\
\hline Menos de una hora $\ldots \ldots \ldots c c c c c$ & 6,0 & 1,2 \\
\hline De una a dos horas $\ldots \ldots \begin{array}{lllll}\ldots & \ldots & \ldots & \ldots & \ldots\end{array}$ & 27,7 & 8,0 \\
\hline De tres a cuatro horas ... ... ... .. & 32,1 & 182 \\
\hline 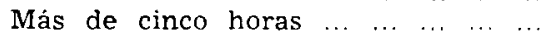 & 26,2 & 67.9 \\
\hline $\begin{array}{lllllllll}\text { No } \text { contesta } & \ldots & \ldots & \ldots & \ldots & \ldots & \ldots & \ldots & \ldots\end{array}$ & 8,0 & 4,8 \\
\hline
\end{tabular}

Total: 336 .

Naturalmente el problema no se limita a la cantidad; la calidad de la relación puede operar subsanándolo. No obstante, los datos me parecen reveladores de los comportamientos que prevalecen en la sociedad española. Incluso la edad de los entrevistados, 12 años, obliga a pensar que en edades más tempranas se reduce la participación del padre y el tiempo dedicado a convivencia con sus hijos. La mencionada encuesta muestra además que cuanto peor se desenvuelve económicamente la familia, menos tiempo dedican los padres a sus hijos. No se piense, sin embargo, que esta convivencia viene condicionada decisivamente por las condiciones materiales de vida o el trabajo extradoméstico del varón. Influyen, desde luego. Pero sobre estas circunstancias se encuentra un hecho básico: asignación cultural de la crianza y cuidado de los niños como tarea específica de la mujer, y no de los padres, lo cual afecta también a la calidad de la relación. A lo sumo se propugna, y practica, que el marido debe «ayudar», nunca compartir por igual. Y no creo que en esta actitud se estén produciendo cambios sustanciales, especialmente entre los varones. En fin, cuando tanto se alude a las penalidades del divorcio bueno será recordar que, sin él, en buena parte los hijos se crían ya sin la presencia del padre.

"EDIs: "El menor marginado" (multicopiado), Ministerio de Cultura, vol. 1.0, 1980, pp. 161-162. Por su parte, el 60 por 100 de los padres declaran pasar poco tiempo con sus hijos; en "Los españoles, padrazos", Cambio 16, núm. 461, 5 octubre 1980, p. 44. 
La ideologia sobre los hijos

Un acusado rasgo de nuestra sociedad lo constituye la gran importancia atribuida a los hijos en la relación matrimonial y a su papel atribuido como estabilizadores, e incluso mantenedores de la cohesión formal, en los matrimonios. Alguien, Carandell, lo ha expresado de manera lapidaria: «Existen en España, a propósito de los hijos, ideas muy claras. Los hijos unen. La mujer es un animal peligroso, hay que dejarla embarazada»". Posiblemente sea en Unamuno donde se encuentren los más brillantes reflejos literarios de esta actitud, en concreto de la mujer, de situar a los hijos en el centro de su existenciá.

Por supuesto, esta visión de los hijos no está circunscrita a España; existe en efecto una larga tradición intelectual que percibe la ausencia de hijos como causa de desunión matrimonial. En este sentido ya Aristóteles pudo escribir: «la amistad entre marido y mujer parece fundada en la naturaleza; el hombre y la mujer cohabitari, no sólo por causa de la procreación, sino también para los demás fines de la vida. Por otra parte, los hijos parecen ser un lazo entre ellos, y por eso se separan más fácilmente los que no los tienen: los hijos son, en efecto, un bien común a ambos, y lo que es común mantiene la unión" ". Muy posiblemente cuando esta observación se formulaba, era atinada. El tipo de familia y el papel desempeñado por los hijos en ella, se correspondia con la estimación de los hijos como vínculo de unión en los matrimonios. Pero como es sobradamente conocido por los estudios de Ogburn, no todos los elementos, materiales e inmateriales, de una cultura tienen un ritmo de cambio sincrónico. Y el papel atribuido a los hijos tal vez constituya excelente ejemplo de un acelerado cambio material, con persistencia de ideologías resultado de otras épocas.

La importancia atribuida a los hijos para la relación matrimonial no aparece, sin embargo, con el matrimonio, ni tampoco es rasgo exclusivo de la mujer. Los numerosos estudios sobre la juventud y universitarios realizados en nuestro país, en todos aparece esta dimensión también entre los varones. Cuando se pregunta sobre las cualidades ideales de la novia, figura siempre en los primeros lugares «amante del hogar y de los hijos». Lo de menos ahora es el tradicionalismo que esta orientación comporta, intentando evitar que la mujer asuma nuevos papeles sociales. Lo relevante es que a edades tempranas estos entrevistados configuren como expectativa básica del rol de la mujer su papel de madre que, en la posterior dinámica de la relación conyugal, su desenvolvimiento puede obstaculizar el logro de expectativas centradas en la propia relación. En cualquier caso, ya desde los primeros es-

L. Carandell, Los españoles, Barcelona, ediciones de bolsillo, 1971, p. 95.

"Véase tratado, entre otros, en J. Rof Carballo, "El erotismo en Unamuno". Madrid, Revista de Occidente, núm. 19, 1964; F. SchurR, "El amor, problema existencial en la obra de Unamuno", Buenos Aires, Cuadernos del Idioma, volumen 1.", núm. 1, 1965.

Aristóteles, Etica a Nicómano, Madrid, ed. IEP, 1970, p. 136. 
tudios sobre natalidad se observaron diferencias significativas en el número ideal de hijos deseados, siempre superior para las solteras. Como Díez Nicolás escribió: «El mayor tamaño ideal señalado por las solteras puede atribuirse al hecho de que su contestación responde a una idea más romántica y menos real de la responsabilidad y dificultad que supone el criar y educar a muchos hijos; las casadas, por el contrario, al estar en contacto directo con estos aspectos de la vida familiar, puede que den una contestación teniendo en cuenta más directamente la realidad de la vida familiar de nuestros días» ${ }^{3}$. Hay en todo caso una expresión, habitual en nuestra sociedad, reveladora de esta ideología natalista; a un matrimonio joven nadie le preguntará sobre si piensan o no tener hijos, tan sólo el momento - ¿Cuándo vais a tenerlos? - considerado ineludible.

Similar orientación se constata en estudios referidos a población casada. Así en una encuesta del Instituto de Opinión Pública en 1968, el 62 por 100 de los entrevistados estaban de acuerdo con que «lo más importante no es el éxito propio, sino el de los hijos». En el de López Pintor y Buceta, el 29 por 100 de los varones y el 43 por 100 de las mujeres consideran que «los niños son lo más importante de mi vida». Otra encuesta de 1978 revela que para el 32 por 100 de los entrevistados tener hijos y con un buen futuro profesional, es lo más importante que espera en la vida familiar. En fin, el 51 por 100 de los entrevistados en 1980 piensan que lo que asegura la más completa realización del individuo es la maternidad y la paternidad?

Esta tendencia se proyecta también para el supuesto en que aparezcan tensiones matrimoniales. Parece una verdad irrefutable que lo peor que a los hijos puede sucederle es la separación de sus padres, por muy tensas e incluso violentas que lleguen a ser esas relaciones. Se trata de un valor común aun cuando no existan estudios sobre este aspecto en España y los de otros países revelan que se trata de una creencia errónea. Pero veamos en todo caso algunos datos que la confirman. En la investigación de Díez Nicolás sobre mujeres casadas de hasta 45 años, el 72 por 100 (es decir, tres de cada cuatro entrevistadas) están de acuerdo o muy de acuerdo con que «cuando hay hijos, los padres deben seguir viviendo juntos aun en el caso de que no se lleven bien». En el Foessa de 1975, tan sólo el 15 por 100 está de acuerdo con que «el matrimonio no tiene por qué permanecer unido cuando se lleve mal, aunque haya hijos pequeños» En otra encuesta de 1977, para un semanario, el 80 por 100 de los entrevistados de uno y otro sexo entienden que «los hijos salen perjudicados cuando una pareja se divorcia». Los datos

* J. Díez Nicolás, "Status socioeconómico, religión y tamaño ideal de la familia urbana", REOP, núm. 2, 1965, p. 102.

${ }^{4}$ Los datos mencionados pueden ampliarse, respectivamente, en IOP, "Encuesta sobre la imagen del mundo en el año 2000", REOP, núm. 13, 1968, pp. 319-320; R. López Pintor y R. Buceta, Los españoles de los años setenta, Madrid, Tecnos, 1965 , pp. 133 y 178; Cambio 16, "Encuesta sobre la familia española", núm. 360, 26 octubre 1978, p. 87, y Cambio 16, "Los españoles, padrazos", núm. 461, 5 octubre 1980, p. 43. 
del Centro de Investigaciones Sociológicas de 1978 van en la misma dirección; el 37 por 100 responde que lo preferible para los hijos, si los padres se llevan mal, es que vivan juntos ${ }^{10}$.

Nadie puede discutir que, hoy por hoy, la situación ideal para el niño es que conviva con una pareja cuyas relaciones sean armónicas. Pero si este supuesto no se da y existe, por el contrario, una relación conflictiva, está sobradamente comprobado que es preferible la separación a la convivencia con conflictos. Estos son además percibidos con nitidez y sufridos por el niño desde su más temprana edad, y todo intento de enmascararlo es infructuoso. Me remitiré a un tjemplo aleccionador para los científicos sociales. Me refiero a la magistral biografía de Mitzman sobre Max Weber ". Percibió desde su infancia las incompatibilidades y tensas relaciones de sus padres $y$, esa vivencia, le ocasionó hondos conflictos personales con repercusión ulterior tanto en su vida personal, como en sus propias concepciones políticas y científicas. Yo mismo, examinando los procesos de nulidad y separación matrimonial, he observado un efecto, sin duda no deseado, de la ideología sobre los hijos unen al matrimonio. A menudo cuando la situación matrimonial ya es conflictiva, $y$ sin posibilidad razonable de armonía, no faltan presiones (habitualmente a través de la mujer) para que intente estabilizar el matrimonio con un nuevo hijo. A la postre el matrimonio se separa, con lo cual el número de hijos implicados se incrementa.

Naturalmente estas creencias sobre el papel cohesionador de los hijos no son resultado del azar. Provienen del influjo religioso secular en favor de la natalidad (también para mantener el papel tradicional de la mujer) y que ha coincidido casi siempre con la postura del Estado. Ideologías natalistas que se traducen en fuertes presiones, durante el proceso de socialización, encaminadas a que la mujer asuma como expectativa vital básica la maternidad y el matrimonio ${ }^{12}$. En su apoyo vendrán, además, estereotipos como

"Véanse, respectivamente, J. DíEz Nicolás, "Comportamiento familiar de la mujer casada en España", Gentleman, Madrid, núm. 3, junio 1973, p. 50; Fundación FOESSA, Estudios sociológicos sobre la situación social de España, 1976, p. 397; Cambio 16, "Encuesta aborto, planificación familiar y divorcio", núm. 312. 4 diciembre 1977, p. 32, y C.I.S., "Informe avance sobre las actitudes ante el divorcio y utilización de anticonceptivos", REIS, núm. 1, 1978, p. 387.

${ }^{11}$ A. Mitzmann, La jaula de hierro. Una interpretación histórica de Max Weber, Madrid, Alianza editorial, 1976. En este sentido, ya Freud había señalado que "el desacuerdo reinante entre los padres excita la vida sentimental del niño y le hace experimentar, ya en la más tierna edad, amor, odio y celos. Luego, la severa educación, que no tolera actividad alguna a esta vida sexual tan tempranamente despertada, interviene como poder represor, y el conflicto surgido así en edad tan tierna del sujeto integra todos los factores precisos para la causación de una nerviosidad que ya no le abandonará en toda su vida". en Ensayos sobre la vida sexual y la teoria de la neurosis, Madrid. Alianza editorial. 5." ed. 1972 , p. 42 .

12 La obra de García LoRCA, Yerma, plantea precisamente el tema del matrimonio sin hijos, aunque no pueda entenderse sin tener presente al mismo tiempo algo que -sólo aparentemente- no es el centro de su carga dramática: la profunda interiorización de la inđisolubilidad matrimonial. Su ortodoxia es comple- 
«los niños vienen con un pan bajo el brazo». sobre las consecuencias negativas de los hijos únicos, etc. Todo ello, en definitiva, en coincidencia con la ortodoxia católica respecto a la procreación como fin primario del matrimonio.

En relación a los hijos únicos - de los que carecemos de estudios en España-, debe señalarse que los estereotipos peyorativos que se les atribuyen provienen del incumplimiento de la ideología natalista, más que de auténticos perjuicios sufridos por tales hijos. Por lo menos, en los casos que no se debe al divorcio o muerte de uno de sus padres. Aquí de nuevo tropezamos con la pervivencia de ideologías tal vez explicables en épocas de elevada mortalidad infantil y en donde la baja natalidad pondría en peligro la continuidad de la especie. O cuando una familia numerosa suponía una fuente de ingresos para la unidad familiar y base de apoyo para el logro de los hijos (y no, como hoy, en el esfuerzo individual). Frente a estas circunstancias, se mantienen los rasgos negativos respecto a los hijos únicos cuando han desaparecido por completo los fundamentos que dieron origen a esas ideologías. Muchos estudios han demostrado, en efecto, las ventajas que goza el hijo de una familia poco numerosa. En Francia, por ejemplo, cualquiera que sea el medio social de origen, el éxito escolar de los hijos aumenta cuando desciende la dimensión de la familia; relación que es más acusada a medida que baja la status ocupacional de los padres. Pero ha sido Blake quien pasó revista de las investigaciones sobre ventajas o inconvenientes de los hijos únicos, a igualdad de situación familiar y socioeconómica de los padres. Los hijos, y en menor medida las hijas, únicos cuentan con logros educativos superiores, mejores niveles ocupacionales, mayor satisfacción con su trabajo, optimismo y en los indicadores de felicidad y satisfacción personal mejores niveles. Tampoco su propia estabilidad matrimonial - medida según la tasa de divorcios- se ve alterada negativamente. No existen diferencias con quienes proceden de otras familias reducidas con dos o tres hijos; aunque ambos cuentan con tasas levemente superiores a quienes proceden de familias más amplias. Por el contrario, en sus prácticas reproductivas son marcadas las diferencias. Los hijos únicos tienen y esperan tener menor número de hijos, aunque desaparecen en lo que se refiere al deseo de tener ellos mismos un hijo único. En definitiva, los datos son concluyentes respecto a las ventajas de las familias reducidas, incluidas las de hijo único, respecto a las numerosas ${ }^{13}$.

ta: "Yerma es un biotipo perfecto de la mujer que supedita de manera absoluta lo erótico a lo fisiológico, la sexualidad a la maternidad. Es curioso notar cómo coinciden aquí el más exigente sentido de la naturaleza como creación indefinida y el criterio tradicional de la Iglesia católica con respecto a la vida matrimonial. El acto amoroso sólo se justifica por un afán de paternidad (sic). Yerma está transida de esta idea" (F. Díaz Plaja, Federico Garcia Lorca, Espasa-Calpe, 3. ed., 1961, pp. 207-208).

${ }^{13}$ Las referencias citadas proceden de INSEE, Données Sociales, París, 1974, pp. 136-137, y J. BLAKE, "The only child in America: Prejudice versus perfoman- 
Pudiera suponerse que tan marcada orientación respecto a los hijos proviene, o al menos se traduce, en la esmerada atención que se les presta en la sociedad española. Este fue el juicio acuñado, con éxito ulterior, por Brenan al afirmar: «Es manifiesto que las relaciones de los jóvenes con los otros miembros de su familia se desarrollan con frecuencia sin sombras ni trabas. $Y$ son gente que quiere mucho a los niños. Se ve a cada paso a un hombre joven bien vestido jugando con un chiquillo o haciendo carantoñas a una criatura sin la menor turbación. No se ve mucha timidez, por mucho que los nuvelistas españoles escriban de cortedades. En pocas palabras, se trata de una sociedad a la antigua — victoriana temprana o Segundo Imperio-, pero que comienza a desmoronarse» ${ }^{14}$, O el desmoronamiento ya se ha producido, llevándose con él tan idílicas relaciones con los niños, o no creo en la validez. actual de su observación. Me parecen escasos esos juegos y cuando se producen se trata, las más de las veces, de un «juego ostentatorio», desigual y expresión del dominio del adulto sobre el niño. Es, me parece, un juego con el niño, siendo el propio niño el objeto del juego, y en muy pocas oportunidades comparten un juego adultos $y$ niños.

Por lo demás, existen numerosos indicadores en contra de esa supuesta valoración del niño. Y no me refiero tan sólo a la indiferencia -o lo que es peor: la naturalidad - con que se presencian malos tratos físicos recibidos por los niños en calles y espacios públicos ${ }^{15}$. Piénsese, por ejemplo, en la

ce", Population and Development Review, vol. 7, núm. 1, 1981, pp. 43-55. Los estereotipos negativos sobre el hijo único, al igual que sobre las familias sin hijos, han sido también analizados por D. F. Polrt, "Stereotypes relating to family-size status", Journal of Marriage and the Family (en los sucesivo citado: J.M.F.), vol. 40, núm. 1, 1978, pp. 105-117. Aspectos conexos a los hijos únicos aparecen también en la abundante bibliografía existente sobre el rango de los hijos: primero, intermedio, último, según el sexo, que repercute muy desigualmente sobre su suerte.

I+ G. Brenan, La faz actual de España, Buenos Aires, ed. Losada, 2." ed., 1964, p. 220 ,

1" Malos tratos que contaban además con todas las bendiciones jurídicas. Así hasta la reciente reforma, según el artículo 171 del código civil, el juez podía retirar la patria potestad al padre si trataba al hijo con "dureza excesiva", y según el 420 del código penal que sanciona las lesiones y malos tratos al fijar las penas, establecía: "No están comprendidas en el párrafo anterior las lesiones que el padre causare al hijo, excediéndose en su corrección." M. Fraga (en Legitimidad y representación, Grijalbo, 1973, p. 119) resalta las ventajas de los castigos físicos: "Los hijos de las familias populares - campesinas, obreras- donde subsiste la figura del padre y los castigos físicos, propenden a tener menos desajustes y conflictos que los de las clases medias, donde la división de la autoridad a menudo desconcierta, y donde al utilizarse medios intelectuales de control los problemas tienden a interiorizarse $\mathrm{y}$, por lo mismo, a la perturbación psicológica". Ciertamente, la frecuencia de castigos físicos aumenta a medida que se desciende de clase social; M. Flavia Olivella, "Investigación en programas de disciplina en el medio familiar". Sociología y psicologia jurídicas. Anuario 1982, pp. 167-183, tanto según las informaciones de los niños - de 11 y 12 años- como de sus respectivos padres. El castigo corporal ya fue señalado como uno de los rasgos de "la cultura de la pobreza" por O. Lewis, La cultura de la pobreza, Barcelona, Anagrama, 1978. Véase también M. E. SÁnchez Morso, "Padres torturadores", en Varios Autores, Contra la tortura, ed. Fontanella, 1978, pp. 124-138. 
insuficiente atención médica recibida por las madres durante el embarazo y parto; la inexistencia de centros de planificación familiar; en la ausencia en los primeros días de la vida de un niño de exámenes por si sufre alguno de los trastornos metabólicos congénitos, fácilmente corregibles, que dan origen a la subnormalidad. Esto en cuanto a la salud física y que ocasiona una mortalidad infantil muy superior a la de Francia y Holanda por ejemplo. Respecto a las cuantías de las prestaciones familiares por hijo, sabido es que son irrisorias y disminuyen sistemáticamente en relación al importe del salario mínimo; no sólo son las más bajas de Europa, su importe es un tercio inferior al país que las tiene más reducidas: Irlanda ${ }^{16}$. Se deduce, pues, que la grandielocuencia en las palabras sirve sobre todo para ocultar la mediocridad de los hechos.

No resulta en todo caso justificada la indiscriminada exaltación de los hijos - y en general la ideología natalistá-, cuando al mismo tiempo el Estado exige para la adopción un examen cuidadoso de las características e idoneidad de los adoptantes. ¿Cómo explicar las precauciones impuestas ante un fenómeno tan minoritario (afecta alrededor de 1.000 niños al año) y simultáneamente se da por hecha la total idoneidad de las familias de los centenares de miles de niños que nacen cada año? Esta indiferencia estatal ante la mayoría de los niños nacidos, me parece particularmente esclarecedora. Aunque no debe olvidarse que hasta la Ley de 7 de julio de 1970, que modificó el Código Civil estableciendo en su artículo 173 el consentimiento de ambos cónyuges para dar un hijo en adopción, hasta esa fecha podía disponer de los hijos solamente el padre, aun en contra de la voluntad de la madre. Lo que desde luego bien poco dice del respeto, en la práctica, a la maternidad. Pero precisamente como reacción frente a la presunción de idoneidad de los padres, se ha propugnado por la profesionalización de esa tarea para que se asuman las funciones de crianza por cuenta ajena: "A fin de cuentas, la crianza de los niños requiere una competencia que no está en modo alguno al alcance de todos. Nosotros no permitimos que "cualquiera» practique cirugía del cerebro o, por igual motivo, venda acciones u obligaciones. Incluso el funcionario de menor categoría tiene que aprobar exámenes

Para otros paises, véase $H$. Erlanger, "Social class and corporal punishment in childrearing: A reassessment", A.S.R., vol. 39, núm. 1, 1974, pp. 68-85, y la obra de I. Gibson, El vicio inglés, Planeta, 1980. Por su parte, W. Reich (en Materialismo dialéctico y psicoanálisis, Siglo XXI, 1975, p. 120) ya observó que: "Todo padre proletario - las excepciones son contadas- se venga de su servicio de criado en la empresa con el niño, en la casa. Al menos aquí quiere ser el dueño, quiere poder mandar y tener quien le obedezca. Si no es el perro, que sea el niño. Que el pegar a los niños pertenece a este renglón, es cosa obvia."

16 Véase al respecto E. González Sancho, "La política de protección a la familia en España", Papeles de Economía Española, núms. 12-13, 1982, p. 353; también. J. C. Martín ANTón, "La protección a la familia", Información Comercial Española, núm. 554, 1979, pp. 59-64. Referida a la legislación sobre la maternidad en España y otros países, véase C. PAOLI, "Las trabajadoras y la maternidad. Algunos ejemplos de países de Europa occidental", Revista Internacional de Trabajo, Ginebra, vol. 101, núm. 1, 1982, pp. 33-49. 
$\mathrm{d} \epsilon$ competencia. En cambio, permitimos que cualquiera, con independencia de sus cualidades mentales o morales, trate de criar jóvenes seres humanos, con tal que éstos procedan biológicamente de él. A pesar de la creciente complejidad de la labor, la crianza de los hijos sigue siendo el mayor privilegio del aficionado" ${ }^{17}$.

Se produce, en suma, la incompatibilidad radical entre los intereses reales de los niños y el mantenimiento del liberalismo inhibicionista estatal sobre su suerte. El Estado sólo interviene suspendiendo la patria potestad de los padres, en circunstancias límites (para adjudicarles un destino tan poco glorioso como el que les espera en las instituciones tutelares de menores). Son las graves alteraciones en las relaciones entre los padres, y no la situación de los hijos, lo que desencadena la mecánica intervencionista. E igual ocurre en los procesos -eclesiásticos y civiles- de nulidad, separación o divorcio. El objeto de la prueba siempre son las relaciones matrimoniales y para nada juega el bien de los hijos. De ahí que no hayan faltado quienes propugnen ${ }^{18}$ el divorcio forzoso en interés de los hijos.

Por otro lado, la virulencia de las ideologías natalistas han enmascarado un aspecto de la cuestión sumamente importante. Sabido es que el control de la natalidad consiste en aquella acción destinada a evitar posibles embarazos no deseados y se basa en que la procreación es un derecho individual. Planificación familiar es un concepto más amplio y no se refiere sólo a técnicas anticonceptivas. Consiste en el derecho de toda persona (no implica pues uniones legales) a decidir libre y responsablemente el número y espaciamiento de sus hijos. Incluye el derecho de todo niño a ser un hijo deseado por sus progenitores y a desarrollar su existencia en condiciones materiales y espirituales adecuadas. Pero comprende tanto las conductas destinadas a evitar tener hijos, como para tenerlos. Se producen por tanto comportamientos encaminados al control de la natalidad, que es en el único aspecto en donde se han centrado los alegatos contra los métodos eficaces y modernos en nuestro país. $Y$, sin embargo, un persistente silencio de los mismos grupos natalistas se observa respecto a medidas para solucionar la situación de los matrimonios sin hijos. Alrededor de un 10 por 100 de los matrimonios se enfrentan a la situación inversa: no tener descendencia que, sin embargo, desean. Pese a ello no se ha facilitado sustancialmente la adopción, lo que por otra parte favorece un floreciente «mercado negro» de adopciones. Además, la Seguridad Social no cubre el tratamiento de la esterilidad y, menos aún, la inseminación artificial, aspectos que para colmo tampoco se estudian en las Facultades de Medicina. En definitiva, no parece que la preocupación por

17 A. Toffler, El "shock" del futuro, ed. Plaza y Janés, 3." ed., 1971, p. 258.

18 Esta fue, por ejemplo, la propuesta realizada, durante el debate de la Constitución de la II República, por el médico y diputado Dr. Juarros en favor de "crear un divorcio forzoso para aquellos casos donde los padres no quieren divorciarse, pero el interés de los hijos obligue a separar el matrimonio"; D.S.C.C.. 8 octubre 1931, p. 25. 
los hijos sea sustancial, salvo en lo que a proclamaciones verbales se refiere. Todo ello sin recordar su incompleta escolarización, ritmos escolares al servicio de intereses de los adultos, configuración de la ciudad y organización del espacio a espaldas de las conveniencias de desenvolvimiento de los niños, el lamentable estado de las instituciones de acogimiento de niños (hospicios), etc. Parecen satisfechos con promover que los niños nazcan, olvidando que, al cabo, en efecto nacen. Subsiguiente obligación ineludible, por parte de la sociedad, es ofrecerles una atención y calidad de servicios desconocida en España, comparativamente en situación muy desfavorable al resto de países del este y oeste de Europa. Pragmáticamente, nos limitamos a proclamar y defender los derechos de los niños en abstracto y a conculcarlos en la práctica.

Pero quisiera para terminar aludir al continuo silencio percibible en la literatura apologética sobre la natalidad. Se trata de los hijos no deseados. Descargan los más negros presagios sobre las consecuencias del control de la natalidad, para la salud - física y espiritual- de la mujer, la dignidad de la pareja y la misma armonía y estabilidad de la familia ${ }^{19}$. Pero para nada mencionan la existencia de natalidad no deseada y sus consecuencias.

\section{Los bijos no deseados}

Se ha vinculado con demasiada frecuencia la ilegitimidad con la natalidad no deseada. $Y$, sin embargo, ni todos los hijos legítimos son deseados, ni todos los ilegítimos no deseados. En especial durante la década de los setenta en que se ha roto la tendencia secular a su disminución, el aumento de la ilegitimidad procede en buena parte, también en España, de uniones de hecho o mujeres que impugnan el matrimonio pero desean tener hijos.

En España, pues, el sector estratégico para analizar la natalidad no deseada debe centrarse en el matrimonio. $Y$ todos los datos confirman las elevadas tasas de natalidad no deseada. Numerosos estudios han puesto de relieve las grandes dosis de discriminación legal y social de la mujer que todavía subsisten en nuestra sociedad; la sexista estructura de autoridad en la familia y división del trabajo; la socialización diferencial por sexo y, en general, el tradicionalismo de las relaciones intersexuales y conyugales. Cir-

19 Así, Escrivá de Balaguer dirá: "Podría escribir un grueso volumen sobre las consecuencias desgraciadas que, en todo orden, lleva consigo el uso de esos u otros medios contra la concepción: destrucción del amor conyugal -el marido y la mujer no se miran como esposos, se miran como cómplices-, infelicidad, infidelidades, desequilibrios espirituales y mentales, daños incontables para los hijos, pérdida de la paz en el matrimonio", en Conversaciones con Mons. Escrivá de Balaguer, Madrid, ed. Rialp, 1968, p. 143; curiosamente, omite la repercusión en la salud física de la mujer, que ha sido la única constatada por los investigadores. En torno a las ideologías sobre la natalidad en España, véase A. de Miguel, Sexo, mujer y natalidad en España, Edicusa, 1974. 
cunstancias todas ellas que conducen inevitablemente a la elevada proporción de natalidad no deseada: «Los estudios de parejas casadas en las zonas predominantemente urbanas de los países industrializados y en desarrollo indican que cuanto más equitativa o no tradicional es la división del trabajo (incluida la adopción de decisiones) en el hogar, tanto más probable es que las parejas:

a) Se comuniquen entre sí con respecto al sexo, sus preferencias en cuando al tamaño de la familia y la planificación de los nacimientos.

b) Den cuenta de un alto grado de satisfacción sexual.

c) Expresen el deseo de tener una familia pequeña; y

d) Practiquen una contracepción eficaz» ${ }^{20}$.

Entre otras muchas investigaciones, la realizada por Díez Nicolás en 1972 sobre Natalidad y planificación familiar, permite constatar la frecuencia de este fenómeno en la sociedad española. En base a una muestra nacional de cerca de 2.000 mujeres casadas de 15 a 49 años de edad, sólo la mitad de las mujeres entrevistadas afirmaron que habían tenido su último embarazo cuando lo deseaban. De igual manera, el 58 por 100 responde que su marido quería tener un hijo cuando comenzó su último embarazo y el 33 por 100 afirma que nunca habla con el marido sobre el número de hijos que quieren tener. La experiencia de trabajo extradoméstico de la mujer es un factor diferencial importante. En efecto, la proporción de mujeres que quería tener su último hijo cuando lo tuvo, cuyo último embarazo comenzó cuando quería y que espera tener los hijos que quiere, en todos los casos es sustancialmente superior entre las mujeres que han trabajado, trabajan o esperan trabajar en el futuro ${ }^{21}$.

La magnitud de la natalidad no deseada puede comprobarse también en la Encuesta de fecundidad: Metodología y resultados llevada a cabo por el Instituto Nacional de Estadística en 1977, a una muestra de cerca de 6.000 mujeres no solteras de 15 a 49 años de edad en toda España. Pues bien, la proporción de embarazos no queridos es alta: un 28 por 100 de las mujeres no deseaban su último embarazo. Por supuesto, la no deseabilidad del embarazo asciende con la edad de las entrevistadas. Pero lógicamente importa más examinar las respuestas según el número de hijos tenidos y aquí se produce también una relación lineal; cuando aumentan se incrementa igualmente la proporción de mujeres que no deseaban su último embarazo:

20 Naciones UnIdas, La condición de la mujer y la planificación de la familia, Nueva York, 1975, p. 67.

${ }^{2 t}$ Véase J. Dízz Nicolás y J. M. de Miguel, Control de natalidad en España, ed. Fontanella, 1981, pp. 115-121 y 293. También la natalidad no deseada es elevada en EE. UU., en especial en la población negra; véase $K$. E. Bauman y J. R. UdRY, "The difference in uniwanted births between blaks and whites", Demography, vol. 10, núm. 3 , 1973, pp. 315-328. 


\begin{tabular}{|c|c|c|}
\hline & Nümero de hijos vivos & $\begin{array}{l}\text { No deseaban el } \\
\text { último embarazo }\end{array}$ \\
\hline & 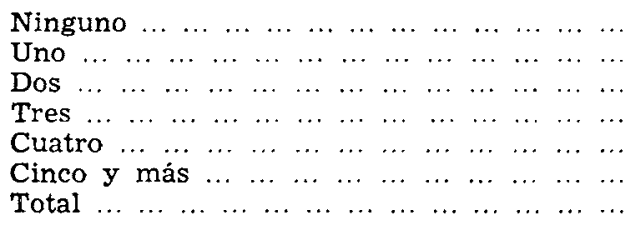 & $\begin{array}{r}1,5 \\
10,7 \\
24,3 \\
38,9 \\
46,4 \\
53,9 \\
27,7 \\
(5.641)\end{array}$ \\
\hline
\end{tabular}

Así pues, si a esta proporción, de cerca de un tercio de mujeres casadas que no deseaban su último embarazo, añadimos que el 61 por 100 no desean tener más hijos y pese a ello menos de la mitad afirman utilizar un método eficaz ${ }^{22}$, la conclusión lógica es que el porcentaje de hijos no deseados de este grupo de mujeres se incrementará todavía más en el futuro.

Los datos mencionados, procedentes de investigaciones realizadas con toda solvencia científica, me parecen suficientemente elocuentes de la magnitud del problema. No se trata, en verdad, de un entretenimiento de sociólogos o demógrafos la natalidad no deseada. Todo lo contrario; tal vez sea muy escasa la atención prestada al fenómeno si lo comparamos con su extensión. Sobre todo por las consecuencias, al menos en otros países, que comporta para la relación matrimonial e incluso los propios hijos. En efecto, la contribución de los hijos a la estabilidad matrimonial está relacionada no con el número real de hijos, ni con el número deseado, sino con el hecho que la pareja logre la natalidad deseada. A. Michel y F. Lautmann han demostrado la relación dialéctica existente entre la calidad de la interacción en la pareja y el logro del número deseado de hijos. La comunicación conyugal, e inversamente: este éxito refuerza el acuerdo, comprensión, comunicación y satisfacción conyugal y, por consiguiente, la interacción conyugal. A medida que el número real de hijos va excediendo al deseado, aumenta también el grado de tensiones y discrepancias entre la pareja ${ }^{23}$. Por lo demás, se han observado consecuencias negativas en el comportamiento del recién nacido si proviene de un embarazo no deseado y el síndrome de niños maltratados se produce, sobre todo, en este mismo grupo ${ }^{24}$.

22 INE, Encuesta de Fecundidad. Metodología y resultados, Madrid, 1978, páginas 112-114, 180, 207 y 217.

${ }^{23}$ A. Michel y F LaUtmann, "Nombre d'enfants et interaction conjugale dans les familles urbaines françaises", Population et Famille, núm. 16, pp. 95-103; Heaty y otros, "A research note on children view as contributors to martial stability: the relationship to birth control use, ideal and expected family size", J.M.F., vol. 36, núm. 2, 1974, pp. 304-306; R. F. Winch, "Marriage and the family", en J. B. GrtTler (ed.), Review of Sociology, Nueva York, ed. J. Willey, 1957, pp. $357-358$.

${ }^{24}$ A. J. FERREIRA, "The pregnant woman's emotional attitude and its reflection on the newborn", en WINCH y Goodman (eds.), Selected Studies in marriage and 
En cualquier caso, tomemos la natalidad no deseada como causa o manifestación de falta de armonía o tensiones matrimoniales, lo que está claro es que tiene incidencid negativa en la ulterior dinámica de la pareja. Todo esto sin tener en cuenta un aspecto de sumo interés, y frecuencia en mi opinión en España, como es si ese hijo no deseado resulta, precisamente, la causa del matrimonio en la pareja. Me referiré de inmediato a la cuestión. Antes quisiera subrayar un aspecto de los estudios sobre natalidad y su control en España. Hasta ahora me parecen centrados - tal vez en demasíaen el cómo y por qué de la contracepción. Al propio tiempo han sido suficientemente comprobadas las pautas moderrias de fecundidad y su control que prevalecen en las cohortes más jóvenes. Acaso la disponibilidad de medios más modernos y eficaces, exigirá investigar sobre todo el porqué de la natalidad. Como ha escrito Bourgeois Pichat, la difusión de esos contraceptivos favorecerá la natalidad deseada decidida por los padres: «Antes que acontecimiento sociobiológico, el nacimiento de un hijo se convertirá en acontecimiento psicológico. Este cambio de naturaleza tendrá importantes repercusiones en la investigación: no bastará saber cómo llegan los hijos, será necesario saber por qué. Sin duda prácticas anticonceptivas totalmente eficaces, es materia todavía del futuro. Sin embargo, los recientes progresos nos han aproximado lo suficiente a esta situación para que la investigación haya tenido que orientarse, en sus perspectivas, hacia le 'porqué' de la natalidad» ${ }^{25}$. Esta perspectiva parece cada día más urgente emprenderla para comprender, debidamente, la futura evolución de la fecundidad en nuestra sociedad.

\section{El matrimonio por los bijos}

En un aspecto sí puede afirmarse con rotundidad que los hijos, si bien no unen a los padres, en ocasiones inequívocaniente los atan. Es decir, los hijos son la causa del matrimonio. Me refiero, en concreto, a los matrimonios contraídos por la existencia de embarazo prematrimonial previo. La idea que el acceso al matrimonio viene motivada por la libre decisión de la pareja -en cuanto al cónyuge y en cuanto al momento de realizarlo- no es más que una norma cultural (reciente, por lo demás) con numerosas quiebras en la práctica. Y ésta es una de ellas.

El matrimonio por razón de embarazo supone la ruptura de esa norma ideal por cuando puede: ocasionar un matrimonio hasta entonces no previsto

the family, Nueva York, ed. Rinehart and Winston, 3. ed., 1968, pp. 259-266; C. y W. M. Russell, Violence, monkeys and man, Londres, ed. Macmillan, 1968, páginas $165-166$.

¿s J. Bourgeoois Pichat, La demographie, París, ed. Gallimard, 1971, pp. 35-36. Una indicación de interés nos la ofrecen las parejas que se someten a inseminación artificial, a resultas de la cual, a principios de 1981 , ya habían nacido $150 \mathrm{ni}-$ ños en España; véase Cambio 16, núm. 486, 23 mayo 1981, pp. 50-56. 
por la pareja - matrimonio provocado-; o bien puede obligar a la pareja a adelantar su matrimonio de alguna manera previsto - matrimonio adelantado-. Y con menor incidencia a nuestros efectos aquí, puede producirse el embarazo poco antes de celebrarse el matrimonio previsto, sin necesidad de alterar por ello los planes matrimoniales ${ }^{26}$. Por supuesto, numerosos factores condicionan la frecuencia de estos diferentes tipos de uniones en cada sociedad y, dentro de cada una, según la clase social. Así, la edad de matrimonio, actitud ante la ilegitimidad, comportamientos sexuales prematrimoniales, religiosidad, grado de difusión y eficacia de los métodos anticonceptivos utilizados, etc.

Pues bien, en lo que se refiere a España, debemos abordar la cuestión en tres dimensiones relevantes: En primer lugar, preguntándonos si la sociedad española impone como norma, caso de embarazo entre solteros previo al matrimonio, el matrimonio como solución obligada. En segundo lugar, examinaré la frecuencia con que se produce el matrimonio por embarazo. $\mathrm{Y}$, por último, cuáles son las consecuencias que para la familia y, en particular, el matrimonio comporta este tipo de matrimonio por razón de embarazo. Veamos cada uno de estos aspectos.

En primer lugar, pues, si el comportamiento esperado caso de embarazo prematrimonial es el matrimonio. Se trata, desde luego, de una norma bastante extendida y que revela la persistencia de la observación de Malinowski ${ }^{27}$ sobre el matrimonio no como licencia para las relaciones sexuales, sino para la paternidad. El matrimonio caso de embarazo previo puede afirmarse que es el comportamiento esperado, e incluso obligado, en la sociedad española. Quizá sea éste uno de los aspectos de las relaciones intersexuales en que menos cambios se han producido desde comienzos de siglo. $\mathrm{Y}$ posiblemente no sufra, tampoco, cambios drásticos en un futuro inmediato. Al contrario, la mayor libertad sexual parece asociada a la mayor frecuencia de este tipo de matrimonios y a la consideración de la obligatoriedad del matrimonio en este supuesto; al menos así lo revelan las estadísticas demográficas y los estudios de opinión para otros países europeos. Lo cual es compatible con la mejora del status legal de la madre soltera y los hijos ilegítimos, atenuación de la censura social y con la impugnación por grupos radicales entre el vínculo matrimonio-procreación.

$\mathrm{Ni}$ la norma cultural ni su puesta en práctica tiende a desaparecer y

${ }^{26}$ F. Prioux Marchal, "Les conceptions prenuptiales en Europe occidentale depuis 1955", Population, vol. 29, núm. 1, 1974, pp. 61-68.

${ }_{27}$ B. Malinowski, "Parenthood. The basis of social structure", en R. L. CoSER (ed.), The family, its structure and functions, Nueva York, St. Martin Press, 1964, pp. 3-19. Una interpretación semejante es la de Simmel, para quien "el matrimonio, sea lo que fuere, es siempre y en todas partes algo más que el comercio sexual. Por muy divergentes que sean las direcciones en que el matrimonio trasciende del comercio sexual, puede decirse que ese trascender de lo sexual es lo que constituye al matrimonio", en Sociologia. Estudio sobre las formas de socialización, ed. Revista de Occidente, 2." ed., 1977, p. 102. 
menos todavía en la sociedad española, en donde dista de encontrarse como hegemónica la mentalidad permisiva. En efecto, en diversos estudios se ha prestado atención a este tema. Aludiré únicamente a una encuesta, realizada en 1976, a una muestra de la población de los dos sexos con más de 18 años. $Y$ se planteó intentando examinar las actitudes ante el matrimonio provocado. A tal efecto se preguntó a los entrevistados: «Si una pareja de amigos, que no son novios ni están enamorados, van a tener un hijo, ¿qué cree usted que deberían hacer?», y a continuación «¿qué cree usted que le aconsejan a ella sus padres en un caso así?», e igual pero referido a qué consejo se daba a los varones. Pues bien, en el caso extremo que se les planteaba - sin ser novios y sin estar enamorados-, más de un tercio de los entrevistados responden que la conducta adecuada no tiene otra salida, pese a todo, que el matrimonio. La norma cultural parece de aceptación general en lo que se refiere a la mujer. Cuatro de cada cinco entrevistados responden que, en tal caso, le aconsejarían que se casara. Y más de la mitad, a los varones ${ }^{28}$. Parece claro, por tanto, la existencia de una clara expectativa de comportamiento que tras el embarazo impone el matrimonio de la pareja. Y para ello se articularán múltiples presiones, como han señalado los antropólogos en sus trabajos sobre comunidades rurales. En todo caso, además, la persistencia de esta norma puede deducirse también de la frecuencia con que se producen matrimonios por embarazo en la sociedad española.

En relación con la segunda cuestión, la frecuencia de embarazos prematrimoniales, contamos desde luego con numerosos estudios sobre países de nuestra área cultural que revelan que son extraordinariamente frecuentes. Sin embargo, no voy a mencionarlos aquí por cuanto podría objetárseme que sus resultados no son extrapolables a España, debido a las diferencias en los comportamientos sexuales de la juventud, en la utilización de anticonceptivos y la despenalización del aborto (con la salvedad que la supuesta mayor permisividad de otros países, se compensaría con anticonceptivos y aborto más difundidos, reduciendo las diferencias entre otros países europeos y España).

Respecto a nuestra sociedad, sin embargo, en estudios de comunidades rurales, los antropólogos nos han alertado con insistencia sobre el emba-

${ }^{2 *}$ Los datos proceden de un estudio inédito sobre "Evolución de la familia española", realizado para el IOP por J. Cazorla y J. Iglesias de Ussel en 1977; véase también mi artículo "El matrimonio por honor", Anuario Estudios Sociales y Juridicos, vols. $10-11,1982$, pp. 465-485. En otros países esta orientación está sólidamente asentada; así en Francia, el 40 por 100 de los varones y 35 por 100 de las mujeres entrevistados consideran que, caso de embarazo, el matrimonio constituye una obligación del varón; el 30 por 100 y 24 por 100 , que el matrimonio es ia solución más conveniente, y el 25 por 100 y 35 por 100 , que el matrimonio no es salida válida obligada y pueden considerarse otras soluciones: RousSEL, L., "L'attitude des divers generations à l'egard du mariage, de la famille et du divorce en France", Population, vol. 26, junio 1971, p. 109. 
razo prematrimonial, que dista de ser una práctica inhabitual. Pero en general han aludido a la presencia de motivaciones como el deseo de constatar el embarazo previo por el papel que el heredero desempeña en ese medio, para obtener una dote más elevada como condición para la boda, para imponer a los padres un cónyuge que estiman no deseable o mecanismo para evitar los gastos de una boda reputada «normal», etc. Me parece, sin embargo que, sin desaparecer por completo este tipo de causas, es preciso tener presente las ocasionadas por el cambio ocurrido en los comportamientos sexuales entre la juventud a partir de los años sesenta. $Y$ respecto a ello existen indicios relevantes sobre la frecuencia de embarazos prematrimoniales. Siquiera sean aproximativos, merecen aludirse aquí.

Una primera pista nos la proporciona la evolución de la tasa de ilegitimidad en nuestro país. Como es sabido, ha venido descendiendo, con pocas salvedades, desde principios de siglo; sin embargo, en la década de los setenta se invierte la tendencia y comienza a aumentar. Y, sobre todo, aumentan los ilegítimos de madres menores de veinte años. Más que resultado de la impugnación del matrimonio o consecuencias de uniones de hecho, este incremento de la ilegitimidad me parece buen indicador de los cambios de comportamiento sexual y, en alguna medida, pueden preceder al matrimonio.

Un segundo aspecto a considerar se refiere a la edad del matrimonio. La tasa de nupcialidad desciende en la década de los setenta, pero la proporción de matrimonios contraídos por varones que cuentan con menos de 20 años (que ha tenido varias oscilaciones desde principios de siglo) aumenta sin cesar desde $1960 \mathrm{y}$, especialmente, 1979. Este dato lo considero sumamente ilustrativo, pues entiendo que, en su mayoría, involucran matrimonios por embarazo prematrimonial, sean provocados o adelantados. En efecto, ni las edades deseadas de matrimonio que revelan numerosos estudios, ni la situación profesional o de empleo, ni la concepción social vigente sobre la madurez exigida para el matrimonio, ni tampoco la exigencia de realizar con posterioridad el servicio militar (aunque una reciente reforma exime a quien tenga un hijo, si la mujer no cuenta con ingresos), ninguna de estas circunstancias favorece el matrimonio de varones con hasta 19 años, si no es como consecuencia de embarazo prematrimonial. Que, como se sabe respecto a otros países, inciden también sobre parejas muy jóvenes, aunque no sólo en ellos.

La tercera referencia corrobora los indicios señalados sobre la frecuencia de embarazos prematrimoniales. Me refiero a los datos suministrados por el Instituto Nacional de Estadística en la Encuesta de fecundidad realizada en 1977, en base a un estudio entre mujeres no solteras entre 15 y 49 años. $\mathrm{Y}$ aquí ya los datos son concluyentes tanto en lo que se refiere a la frecuencia como a las edades jóvenes de las madres. Examina, en efecto, el intervalo entre el matrimonio y el primer nacido vivo entre mujeres casadas 
desde hace cinco o más años. La distribución porcentual según la edad de matrimonio es la siguiente:

Intervalo entre matrimonio y el primer nacido vivo (en meses)

\begin{tabular}{|c|c|c|}
\hline Edad del matrimonio & Negativo & $\begin{array}{l}\text { De cero a } \\
\text { siete meses }\end{array}$ \\
\hline Menos de 18 años & 1,5 & 14,5 \\
\hline De 18 a 19 años ... & 4,7 & 15,8 \\
\hline $\begin{array}{lllllll}\ldots & \ldots & \ldots & \ldots & \ldots & \ldots\end{array}$ & 3,9 & 14,0 \\
\hline 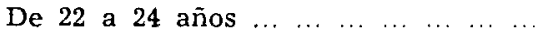 & 3,8 & 11,0 \\
\hline 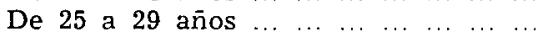 & 3,7 & 13,1 \\
\hline De 30 y más años $\ldots \ldots \ldots c c c c c$ & 10,0 & 10.6 \\
\hline $\begin{array}{lllllllllll}\text { Total } & \ldots & \ldots & \ldots & \ldots & \ldots & \ldots & \ldots & \ldots & \ldots & \ldots\end{array}$ & 4,1 & 12,8 \\
\hline
\end{tabular}

FUENTE: INE: Encuesta de Fecundidad. Metodologia y resultados, Madrid, 1978, p. 95. (Cada fila no suma el ciento por ciento al haber excluido aquí los intervalos superiores a siete meses.)

Obsérvese que se trata de intervalo entre el matrimonio y primer nacido vivo entre mujeres casadas desde más de cinco años en el momento de la encuesta, 1977, o sea, casadas hasta 1972, cuando, ya señalé, desde entonces se incrementan los matrimonios de varones y mujeres de menos de 20 años, y por tanto el subsiguiente aumento escapa del ámbito de esta encuesta. Sin embargo, el intervalo negativo -es decir, primer hijo tenido antes del matrimonio- después de las mujeres casadas con más de 30 años, el más frecuente corresponde a las casadas con 18 y 19 años. Y esta tendencia se refuerza en los intervalos de cero a siete meses. Son sobre todo mujeres casadas con menos de 20 años quienes tienen su primer hijo en ese plazo desde el matrimonio. $\mathrm{Y}$ en total casi un 17 por 100 de las entrevistadas tuvieron su primer hijo antes del octavo mes del matrimonio. En su mayoría pueden considerarse matrimonios por embarazo prematrimonial.

Ahora bien, este tipo de embarazos ¿ocasionan matrimonios provocados —es decir, no previstos por la pareja — o matrimonios adelantados —es decir, previstos pero no en ese momento-? Resulta importante considerar este punto, pues las repercusiones ulteriores en el sistema familiar pueden ser significativamente diversas. En este aspecto, sin embargo, por la ausencia de estudios al respecto, ninguna afirmación concluyente puede efectuarse. En mi opinión, hasta la década de los sesenta se trataba sobre todo de matrimonios provocados, sin que existiera entre la pareja relación afectiva estable. $\mathrm{Y}$ ello porque en contextos tradicionales la tolerancia con las relaciones sexuales del varón fuera del noviazgo, me parece superior a la 
del noviazgo ${ }^{29}$. Por lo tanto, puede suponerse que los embarazos prematrimoniales eran más frecuentes fuera de dicha relación, aunque también daban lugar a ilegítimos o abortos provocados. En una fase de transición y consolidación de la permisividad, como la actual, me parece que cambia la tendencia por el aumento de los matrimonios adelantados; es decir, en parejas con relaciones afectivas estables o en uniones de hecho sin objetivo matrimonial (al margen para nuestros efectos aquí, también aumentan los hijos de parejas o mujeres que desean hijos rechazando el matrimonio). Pero aunque sean más frecuentes los adelantados, continúan produciéndose también, en menor medida, provocados.

He examinado la existencia de normas culturales que imponen como solución obligada el matrimonio, cuando se produce embarazo prematrimonial, y hemos visto su frecuencia en la sociedad española que, hoy en día, fundamentalmente, corresponde al adelantado. Trataré ahora de examinar sus consecuencias respecto al matrimonio.

¿Cuáles son, pues, las consecuencias del embarazo prematrimonial para el matrimonio? De entrada, es preciso recordar que las relaciones sexuales prematrimoniales carecen de efectos negativos ulteriores en el matrimonio. Pero la cuestión puede ser diferente si a consecuencia de esas relaciones se produce un embarazo y el subsiguiente matrimonio. En este caso los hijos atan, pero todo parece indicar que no por mucho tiempo, ya que la inestabilidad matrimonial y las rupturas son particularmente frecuentes.

En todo caso lo que numerosos estudios referidos a otros países han comprobado, es que el divorcio es mucho más frecuente entre matrimonios contraídos a consecuencia de embarazo previo que entre quienes su primer embarazo fue posterior al matrimonio (aunque todavía tienen tasas más elevadas de divorcio las mujeres cuyo primer hijo fue ilegítimo). Dentro del grupo de mujeres con embarazo prematrimonial, se producen más divorcios cuando el matrimonio se retrasa hasta muy poco antes del nacimiento esperado (lo que ocurre sobre todo en parejas jóvenes). En este caso, además, el matrimonio dura menos tiempo, pues el divorcio se produce antes. Cuando el embarazo prematrimonial se produce en un medio social o familiar tradicional, reduce también la estabilidad y duración del matrimonio, más que si se produce en un contexto permisivo ${ }^{30}$.

${ }^{29}$ En sentido contrario, Víctor PÉREz Díaz señaló que, en el medio rural, "no se piensa que los novios esperen tanto tiempo. Se imagina más bien una actividad sexual completa. Y prueba de ello es la difícil salida matrimonial de las muchachas que, al cabo de cierto tiempo, rompen su noviazgo. Se cuenta con tal actividad, pero relegada al margen de la sociedad, fuera de su campo de visión. La comunidad la sabe o la supone; pero no puede admitirla públicamente", en Estructura social del campo y éxodo rural, ed. Tecnos, 1966, p. 96. Yo no creo que existiera ese automatismo entre actividad sexual y dificultad para un nuevo noviazgo de la mujer.

${ }^{30}$ Sobre estos aspectos, véanse L. Bumpass y J. A. Swet, "Diferentials in marital instability: 1970", A.R.S., vol. 37, 1972, pp. 754-764; CoMISSARIAT GÉNÉral du Plan, la famille, París, ed. Hachette, 1975, p. 99; MINISTERe de la Justice, Le 
No obstante, tampoco puede concluirse que la inestabilidad matrimonial sea consecuencia obligada del embarazo previo. Estos matrimonios se encuentran en efecto ante numerosas circunstancias que facilitan la aparición de conflictos. Las presiones familiares y sociales a que la pareja se ve sometida en el breve plazo con que cuentan antes de contraer matrimonio y teniendo además que adoptar decisiones inmediatas de todo tipo; la frecuente crisis con las familias de origen; la erosión que sufre el principio del consentimiento, base teórica del matrimonio en nuestro sistema cultural; las edades jóvenes de la pareja y las dificultades económicas a que han de hacer frente; el inmediato nacimiento del hijo que reduce casi totalmente el período de ajuste personal entre los cónyuges; el que favorezca los procesos de movilidad social descendente; el probable abandono, al menos temporal, de estudios u ocupaciones por parte de la mujer con el alejamiento de sus relaciones personales habituales. Por la concurrencia de alguno de estos factores, los matrimonios por embarazo - tan fomentados una vez aparecida la causa que los origina-, cuentan con suficientes circunstancias adversas como para suscitar elevadas tasas de divorcio. Sólo un cambio muy sustancial del sistema de valores y actitudes sociales harian menos frecuentes en el futuro los conflictos en estos matrimonios y también los matrimonios tras el embarazo.

En la sociedad española dos factores han debido afectar particularmente la estabilidad de los matrimonios por embarazo. En primer lugar, por el rechazo de la pareja por las familias de origen que parece ser, y al menos ha sido, lo usual en la clase media y alta. En tal actitud prevalecen, evidentemente, consideraciones sociales de vulneración de la honorabilidad burguesa, sobre las religiosas. No es, desde luego, una sanción por el incumplimiento de un precepto religioso. Tampoco importa, contra lo que pueda suponerse, la relación sexual, sino su consecuencia - el embarazo- que lo hace público. Por otro lado, en sociedades no permisivas y con elevadas dosis de tradicionalismo aparencial, a la reacción familiar por el embarazo se añade, con frecuencia, un mayor distanciamiento motivado por lo impensado y, en apariencia, impensable del acontecimiento. Como alguien, con un deje de ironía ha escrito, no es el libertinaje lo que ocasiona embarazos prematrimoniales: «Las chicas 'fáciles', al igual que los ángeles, nunca quedan embarazadas. Esto les pasa a las chicas 'buenas'; las chicas 'fáciles' en general son demasiado precavidas para que esto le ocurra» ${ }^{31}$. Con este

divorce en France, année 1970, París, 1973, pp. 71-74 y 141-147; E. JAULERRY, "Les dissolutions d'union en France, étudies à partir des minutes de jugement", Population, vol. 26, junio 1971, pp. 165-168; Christensen, H. T., y Miessner, H. H., "Studies in child spacing: premarital pregnacy as a factor in divorce", A.S.R., vol. 18, núm. 6, 1953, pp. 641 y ss. Para una revisión de la literatura sobre las consecuencias del embarazo para la mujer joven, M. Varela Ogando, "La adolescente embarazada: un problema actual", Juventud, núm. 8, 1982, pp. 145-163.

" S. Kaur, "Attitudes à l'egard de l'avortement provoqué", Revue Internationale des Sciences Sociales, vol. 26, núm. 2, 1974, p. 300. 
rechazo de la pareja por el sistema familiar, han debido ser muy frecuentes y bruscos los procesos de movilidad social descendente. Incluso en sociedades donde estos matrimonios cuentan con mayor ayuda de padres y parientes que los contraídos sin embarazo previo - fenómeno que no parece el habitual en nuestro país-, las desventajas económicas de aquéllos subsisten después de bastantes años de matrimonio ${ }^{32}$.

En segundo lugar, no hemos tenido en cuenta los efectos diferenciales de estos matrimonios según medie, o no, una relación afectiva estable en la pareja; esto es, si son provocados o adelantados. Ya antes apunté como hipótesis el cambio de tendencia con incremento de los adelantados. Pues bien, parece que los provocados presentan mayores riesgos de desarmonía matrimonial por cuanto alteran la presunta libertad de determinación del momento de contraer matrimonio y la no menos presunta de elección de cónyuge. Todo ello sin olvidar que la estabilidad matrimonial, como ha señalado Mogey ${ }^{33}$, depende más del momento en que se contrae que incluso de la elección del cónyuge.

\section{El coste de los hijos}

No han faltado voces que cataloguen la disminución del número de hijos como muestra del egoísmo y comodidad de las parejas, que, poco a poco, estuviera invadiendo nuestra sociedad. Sin embargo, nada más falso y rechazable que este tipo de juicios. Basta con un conocimiento superficial del pasado histórico para saber que, en todo él, nunca ha sido tan elevada como en nuestra época la carga -económica, material, afectiva, etc.- que supone la procreación y crianza de los hijos. $\mathrm{Y}$, asimismo, nunca ha estado este proceso centrado de forma tan acusada en la familia nuclear y, en particular, la madre. Ni aquélla en los hijos.

Podrá discutirse si la depedencia y relación casi exclusiva, durante la primera infancia, de los hijos únicamente con dos adultos - sus progenitores- constituye el sistema de crianza más adecuado. Es relativamente reciente y muchos estudios niegan que sea el más conveniente. Nada tiene de azar por ello que la mística de la maternidad sugiera, y se consolidara, a partir del momento en que la crianza de los hijos comienza a conllevar serios problemas y dificultades a sus progenitores. La generalización de la familia nuclear, el paso de los hijos de ser una ayuda económica para la familia a implicar costes elevados, movilidad geográfica, urbanización, incipiente emancipación de la mujer, entre otros, fueron innovaciones sociales

32 L. Coombs, J. Freedman y W. Prat, "Premarital pregnacy and status before and after marriage", A.J. of S., vol. 75,1970 , pp. 800 y ss.; JorgENSEN y otros, "Diadic and social network influences on adolescent exposure to pregnacy risk", J.M.F., vol. 42, núm. 1, 1980, pp. 141-157.

"Mogey en Revue Internationale des Sciences Sociales, núm. 4, 1962, p. 435. 
que acrecentaban la carga de la maternidad y paternidad. De ahí que aparecieran, como elemento amortiguador, toda suerte de compensaciones simbólicas de la realidad.

No en vano la crianza de los hijos, tan sólo en lo material y para la familia supone hoy un elevado coste. Por una parte, costes indirectos. Piénsese, por ejemplo, en las inversiones necesarias de mobiliario, vivienda, tiempo y similares. $\mathrm{O}$ en la reducción del consumo que ocasiona. $\mathrm{O}$ en la disminución de ingresos familiares por abandono - provisional o, todavía con frecuencia, definitivo- del trabajo por parte de la madre (con la consiguiente frustración, con incidencia en la relación de la pareja), cuando se acrecientan los gastos y duración de las tareas domésticas. Más evidentes son todavía los costes directos: alimentos, vestidos, custodia y guarderías, atención sanitaria, educación y juegos, ocios, dinero para propios gastos, etc. Naturalmente, estos costes varían en función de clase social, edades de los hijos, medio rural o urbano de residencia, rango y número de hijos. En una familia de dos hijos el coste del primero es el doble del segundo; si aumenta disminuye el coste por hijo, pero aumenta el gasto total. Para una familia con un hijo en Estados Unidos se estima que el coste de crianza hasta los 18 años, absorbe entre el 40 por 100 de sus ingresos si es de la clase baja y el 26 por 100 si es de la clase alta. Referido a 1976, para España se ha estimado que el coste mínimo diario de crianza de un niño de hasta dos años, 200 pesetas; hasta cinco años, 300; hasta nueve, 350 , y hasta 14 años, 400 diarias $^{34}$. Es decir, entre 6.000 y 12.000 pesetas mensuales, de coste mínimo hace seis años. E incluye exclusivamente parte de los costes materiales o directos. Si a ello añadimos los indirectos, relacionados con el cuidado y crianza del niño —en gran parte a cargo de la mujer-, la magnitud del coste total del hijo alcanza una dimensión ciertamente elevada.

Desde luego, en nuestra sociedad, en virtud de las reducidas ayudas económicas estatales y la insuficiencia de servicios públicos, en que el coste de los hijos recae exclusivamente sobre la economía de la pareja, esta situación guarda notorias relaciones con el descenso de la natalidad. Cada vez es más cara su crianza y, de continuar, pronto se considerará al hijo como

${ }^{34}$ La estimación de costes para España en F. Villota, "La economía en la política social de la infancia", en VARIOS AUTOREs, El derecho a una infancia feliz, ed. Ministerio de Cultura, 1978, pp. 115-123. La referencia a EE. UU. en L. y J. Scanzoni, Men, women and change. A sociology of marriage and family, McGraw Hill, 1976, pp. 373 y ss. Una estimación para Alemania en M. SPERR, Los padres domados, Barcelona, Grijalbo, 1974, p. 66. Véanse también L. W. Hofrman y J. D. Manrs, "The value of children in the United States: a new approach to the study of fertility", J.M.F., vol. 41, núm. 3, 1979, pp. 583-596, y V. A. ZaLIZER, "The price and value of children: the case of children's insurance", A.J. of S.. vol. 86, núm. 1, 1981, pp. 1036-1057. Un planteamiento metodológico para el análisis del costo de los hijos en C. Presvelou, Sociologie de la consommation familiale, Bruselas, 1968 , cap. 12 ; y su repercusión en el nivel de vida, A. MonNiEr, "Le naissance d'un enfant. Incidences sur les conditions de vie des familles", Cahiers Institut National d'Etudes Demographiques, París, 1977, 240 pp. 
un lujo fuera de (para la mayoría) su alcance. Sin olvidar que dichos costos obligan a emprender readaptaciones en la economía doméstica (el pan que se asegura traen bajo el brazo no es manjar apreciado hoy en exceso) y reajustes entre los cónyuges. Ciertamente, muchas de las disputas matrimoniales por causa de los hijos - a las que luego me referiré- tienen sus raíces en la sombría perspectiva económica que éstos pueden llegar a significar. Debido, sustancialmente, a la ausencia de una política social decidida de protección de la infancia.

En todo caso que la natalidad se encuentra condicionada por la evolución del coste económico de los hijos, ha sido constatado para España. Así, en la ya citada Encuesta de fecundidad: Metodología y resultados, del INE (págs. 146-149), se preguntó a mujeres casadas y no embarazadas que no desean tener más hijos, las razones para no desearlos. Una de cada tres alude, en concreto, a razones económicas, y es la mencionada con mayor frecuencia (36,3 por 100), a lo que habría que añadir el reducido porcentaje de quienes señalan circunstancias vinculadas a lo económico, como la vivienda pequeña o la carencia de guarderías. Esta actitud corresponde, sobre todo, a quienes cuentan con dos o más hijos y a las mujeres en cohortes de matrimonios más recientes; es decir, quienes cuentan con mayor potencial de fecundidad. Por ello responden también, la mitad de las entrevistadas, que el aumento de ingresos familiares sería la principal condición que pudiera hacerles cambiar de actitud respecto a la dimensión de la familia.

Que sepamos, la única aproximación al coste económico de los hijos se efectuó en 1976 en un estudio, para el entonces Instituto de la Opinión Pública, dirigido por el profesor Cazorla y yo mismo. Se les preguntaba en efecto a los entrevistados lo siguiente: «Si una familia como la suya tuviera otro hijo, ¿cuánto dinero de más tendría que gastar cada mes, aproximadamente, para poder vivir de la misma manera?»; los porcentajes son los siguientes:

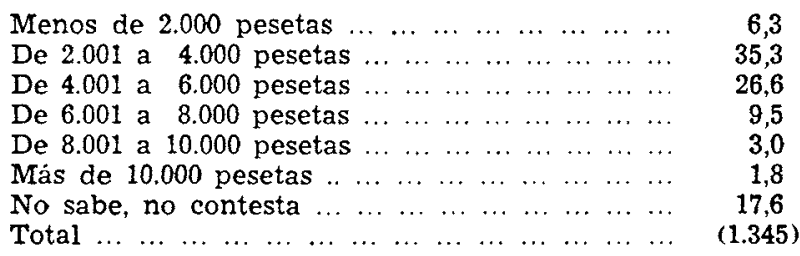

Los entrevistados cuentan con una evaluación precisa del coste adicional de un nuevo hijo. Para el 60 por 100 ese coste se sitúa entre las 2.000 y 6.000 pesetas mensuales; insisto, referidas a 1976. Las variables más discriminatorias son el nivel de ingresos y la clase social subjetiva. $\mathrm{Y}$ ambas operan, claro está, en la misma dirección. Al aumentar tanto los ingresos 
como la clase social declarada, lo hace también el porcentaje de quienes consideran cantidades superiores para mantener su nivel de vida con un nuevo hijo. Ni el sexo de los entrevistados ni, sorprendentemente, la edad introducen variaciones significativas, $y$ no disponemos de los resultados según el número de hijos que ya cuentan. Poco importa, en definitiva, puesto que las cantidades reseñadas contrastan visiblemente con las 250 pesetas por hijo que, todavía en 1982, se asignan por hijo en concepto de ayuda familiar.

En el pasado, el coste por hijo ha debido ser muy discriminatorio según el sexo. Sobre todo por la inversión en enseñanza, muy inferior para las hijas. Hoy tienden a igualarse por el incremento de estos gastos y la disminución de otros - ajuar, etc.-, antes específicos para la mujer ${ }^{35}$. Igualmente me parece que en el coste de los hijos, según la clase social, las diferencias relativas son más acusadas en la actualidad que en el pasado (con todo lo que comporta en la reproducción de la desigualdad social). Y en términos económicos también ha aumentado la inversión requerida para la crianza de los hijos; aunque como contrapartida se haya reducido en algunos casos el tiempo dedicado a algunas tareas. Los efectos de la publicidad han convertido a los niños en cauces de florecientes industrias alimenticias, juguetes, moda infantil, etc. Sin duda, la principal homogeneidad del niño con el adulto se produce hoy en el papel de consumidor, real o truncado. En todo caso, el acusado deterioro de la situación económica familiar por los hijos, repercute negativamente en la relación de la pareja. Los gastos de la casa son una de las principales causas de disensiones en el matrimonio. Por otro lado, que la ruptura matrimonial aumente, en otros países, cuando se desciende de clase social, guarda relación también con las adversas condiciones de vida que agravan los hijos. La ausencia de medidas públicas destinadas a corregir, o al menos paliar, esta situación obliga a pensar en la continuidad de las negativas consecuencias de los hijos en este aspecto.

\section{Los bijos y la relación matrimonial}

El estudio de las relaciones entre los hijos y los padres se encuentran viciadas como consecuencia de la hegemonía del mundo adulto. Contemplamos habitualmente el fenómeno desde la perspectiva no del niño, sino de sus padres. Salvo en la excepción de la creencia que une a los padres, nos preocupamos las más de las veces en nuestra influencia sobre los niños: en el logro educativo, práctica religiosa, actitudes políticas, etc. Esta orientación, al margen de comportar una visión del mundo desde el adulto, me

${ }^{35}$ M. R. Rosenzweig, "Child investment and women", en C. B. Lloyd, Sex, discrimination, and the division of labor, Nueva York, Columbia University Press, 1975, pp. 269-292. 
parece insuficiente por completo. Las relaciones y condicionantes entre padres e hijos son mutuas, y de ninguna manera unidireccionales. Precisamente aquí voy a invertir el enfoque habitual para fijarme en la otra cara, en las repercusiones que los hijos van a ocasionar en la vida matrimonial. Porque, como se ha dicho: «Igual si el hijo lo es del deseo que si lo es del azar, el niño va a alterar la vida de sus padres» ${ }^{36}$. Pero ¿en qué aspectos?, ¿con qué consecuencias?

A nivel teórico Simmel examinó el fenómeno con agudeza y acierto. La llegada de un hijo introduce cambios mucho más relevantes que el meramente cuantitativo. Supone, en efecto, el paso de la díada matrimonial a la tríada: la pareja y el hijo. Con el cambio numérico van a alterarse las relaciones internas profundamente; cada uno de los elementos funciona como intermediario de los otros dos, desempeñando la «doble función propia de todo intermediario, que lo mismo liga que separa». Esta es la mutación básica por cuanto las relaciones de dos tienen rasgos específicos que se transforman al pasar a ser de tres, pero de continuar extendiéndose a cuatro o más miembros: «no siguen modificándose en proporciones correspondientes. Así, por ejemplo, el matrimonio con un hijo tiene un carácter totalmente distinto del matrimonio sin hijos; pero ya no se diferencia tanto del matrimonio con dos o más hijos. Sin duda, la diferencia que introduce en su ser interior el segundo hijo, es, a su vez, mucho más considerable que la que resulta del tercero. Pues el matrimonio con un hijo es, en cierto sentido, también una relación de dos miembros: los padres, como unidad, por un lado, y el hijo, por otro. El segundo hijo no es sólo un cuarto miembro, sino también, considerado sociológicamente, el tercer miembro de una relación, y produce los efectos de tal». Por tanto, «la (relación) de tres se diferencia específicamente de la de dos hacia atrás, por decirlo así, pero no hacia adelante, pues, ya no hay diferencia entre ella y la de cuatro o más elementos» ${ }^{37}$.

Simmel señala el doble papel desempeñado por el primer hijo que une tanto como separa y dirá, en conseguida metáfora, «del mismo modo que un puente, aunque une las dos orillas, hace perceptible la distancia que existe entre ellas». En efecto, entiende que la relación diádica tiene como rasgo básico la intimidad que, cuando nace un hijo, impide que continúe siendo la relación exclusiva que era y puede representar una amenaza o interferencia a la intimidad que «se interrumpe incluso en el matrimonio, tan pronto como ha nacido un hijo». Pues «en toda asociación de tres, por estrecha que sea, hay ocasiones en que uno de los tres es sentido como un intruso por los otros dos"; y este papel no corresponde necesariamente al hijo. Existe una abundante literatura clínica sobre el niño como rival. Las

to SPERR, Los padres domados, op. cit., p. 63.

3 G. Srmmel, Sociología..., op. cit., pp. 105-106, 109 y 112, los entrecomillados y, en general, pp. 91-146: K. H. WoLfF, The Sociology of Georg Simmel, Free Press of Glencoe, 1964, pp. 122-133 y 326-330. 
alianzas también pueden establecerse entre el hijo y uno de sus padres, convirtiendo al otro en intruso, pero en todo caso con quiebra de la pura reciprocidad imperante, hasta entonces, entre la pareja. De igual manera, el niño puede desempeñar la función de mantener unido el todo, vinculando a los otros dos: "Esto puede acontener de dos maneras. O bien la existencia del tercer elemento crea, o fortalece, la unidad de los dos - como cuando el nacimiento de un hijo acrecienta el amor mutuo de los esposos o al menos del marido por la mujer-, o bien la relación de cada uno de los dos con el tercero crea un vínculo nuevo e indirecto entre ellos, como cuando los cuidados dedicados al hijo representan un lazo que trasciende del hijo mismo, y a veces consiste en simpatías que no podrían surgir sin esa situación intermedia» ${ }^{38}$.

Simmel es ciertamente un teórico del desencanto que los hijos originan en la relación matrimonial. Sugiere que tienden a confundirse las intimidades cotidianas con una relación íntima, y paulatinamente las dimensiones más importantes de la personalidad van insertándose fuera de la relación conyugal. Porque no es el contenido de una relación lo que la hace íntima, sino la concepción mutua que la relación, en sí misma, es el lazo esencial de la díada. Sus pioneras reflexiones, justa es decirlo, han tenido efectiva comprobación en numerosas investigaciones ulteriores. Con unanimidad inhabitual en las ciencias sociales, todas ellas han revelado que los hijos introducen importantes cambios en la relación matrimonial susceptibles de originar conflictos. Y ya no nos referimos a las consecuencias económicas. La llegada del primer hijo ocasiona un rápido deterioro del ajuste matrimonial y, particularmente la mujer, experimenta un inmediato y significativo descenso de la satisfacción conyugal desarrollando sentimientos negativos respecto al matrimonio.

La llegada del hijo exige a los padres rápida adaptación a los nuevos roles de la paternidad y maternidad. Transición un tanto abrupta que va a ocasionar la modificación de las tareas domésticas, pautas de ocio, en las relaciones sexuales, además de requerir la atención y cuidados prioritarios por parte de sus padres. Su propia relación, a lo menos en términos de duración y provisionalmente, ha de quedar relegada a un segundo plano. $\mathrm{Y}$ esto ocurre, sobre todo, en el tipo de familia nuclear dominante en nuestra sociedad, y no en la familia extensa, pues hace recaer exclusivamente sobre dos adultos tan absorbentes tareas; en especial en el medio urbano. El informa Foessa de 1975 puso de relieve las diferencias existentes en la ayuda recibida - de familiares, amigos y vecinos - para el cuidado de los niños según el tamaño del municipio, que se reduce en los de más de 100.000 habitantes (que agrupan a la mayor parte de la población). Cuando no se asignan exclusivamente a la mujer. María Angeles Durán indicó que un hijo menor de tres años representa en la jornada de su madre más de dos horas

38 Simmel, op. cit., 99, 98, 106 y 116, respectivamente, los entrecomillados. 
y media diarias de dedicación, al margen de las restantes actividades. En todo caso es claro que el cuidado de los hijos pequeños requiere más tiempo que cualquier otra tarea doméstica. Por ello, sin duda, cuando la mujer lleva poco tiempo casada es el período crítico en que, en España, desciende el número ideal de hijos ${ }^{39}$. Sus consecuencias son particularmente críticas en las parejas donde la mujer trabaja fuera del hogar ${ }^{40}$. Si lo abandona, la pérdida de ingresos y el asumir papeles tradicionales puede convertirse en foco de insatisfacción y tensiones en el matrimonio. Si por el contrario mantiene la actividad extradoméstica, la doble carga del trabajo (el doméstico no se distribuye igualitariamente entre la pareja, ni cuando la mujer trabaja) repercute además en la disponibilidad de tiempo.

La influencia de los hijos en la pareja en el curso de la vida fue certeramente analizado con sofisticada metodología por Harold Feldman. Mostró que la satisfacción conyugal decrece con la llegada del primer hijo, pero sigue una pauta oscilante. Es decir, decrece sistemáticamente hasta la adolescencia de los hijos, para luego aumentar de nuevo al nivel previo a contar con descendencia. Entre tanto los aspectos emocionales del propio matrimonio declinan y son más frecuentes, por ejemplo, las conversaciones sobre temas «objetivos» o instrumentales (sobre la casa, noticias, temas culturales, etc.). Cambios no atribuibles a la duración del matrimonio, pues, siendo igual, los matrimonios con un hijo cuentan con un nivel más bajo de satisfacción que quienes no tienen. Encontró además que el tipo de relación existente entre la pareja antes del parto influye de manera decisiva. Los matrimonios con relaciones menos estrechas, menor grado de comunicación y más tradicionales en la división de tareas domésticas, en ellos el hijo aumenta el grado de satisfacción entre la pareja. Sin embargo, en línea con lo senalado por Simmel, en matrimonios con estrechas relaciones durante el embarazo y alto grado de satisfacción y comunicación interpersonal, la llegada del hijo supone el deterioro de esta situación ${ }^{41}$. Y esta dinámica puede

${ }^{39}$ A. DURÁn, El trabajo de la mujer en España, Tecnos, 1972, p. 116 sobre el descenso del número ideal de hijos; FOESSA, Estudio sociológico sobre la situación social de España, Euramérica, 1970, p. 478; el FOESSA 1975, en op. cit., p. 354. Contra lo que pudiera pensarse, la mecanización reduce más el esfuerzo físico que la duración de las tareas domésticas; para un análisis al respecto, J. B. RoBINSON, "Historical Changes in how people spend their time", en A. Michel (ed.), Family issues of employed women in Europe and America, Leiden, ed. Brill, 1971, pp. 143-154.

${ }_{40} \mathrm{El}$ empleo habitual del término "hogar" sirve, a mi juicio, para ocultar las características negativas que -en superficie, calidad y equipamientos- se manifiestan utilizando el término vivienda; así se sublima la realidad empleando un vocablo que la enmascara.

${ }^{41}$ H. FrLDMaN, "The effects of children on the family", en A. Michel, Family issues..., op. cit., pp. 104-126; SCANzont, Men, women and change..., op. cit.; N. Glenn y S. Maclanahan, "Children and marital hapiness: A further specification of the relationship", J.M.F., vol. 44, núm. 1, 1982, pp. 63-73; ALDRON, H., y Routh, D. K., "The effect of the first child on the marital relationship", J.M.F., vol. 43, núm. 4, 1981, pp. 785-789; R. M. Lerner y G. B. Spanier (eds.), Child influences on marital and family interaction: A life-span perspective, Nueva York, 
devenir más drástica cuando el hijo no era deseado, el matrimonio se ha contraído por causa del embarazo o el hijo nace con minusvalías físicas o psíquicas ${ }^{42}$, que afecta tanto a las relaciones internas como externas de la pareja.

Esta situación se traduce en las tasas de divorcio según el número de hijos. La divorcialidad de las parejas sin hijos guarda relación con la escasa duración del matrimonio y, en cualquier caso, no está claro si la baja fecundidad se debe a la ruptura o la alta tasa de divorcios a la ausencia de hijos. Por otro lado, las presiones apuntadas a favor del mantenimiento del matrimonio con hijos, operan aumentando su estabilidad pero no por la mejor calidad de la relación conyugal, sino por hacer a la pareja reacia al divorcio por el sentido de obligación ante los hijos. El divorcio, pues, es más frecuente entre parejas sin hijos, pero porque es más fácil —psicológica, emocional y económicamente- plantearlo. Contrariamente a las creencias comunes, los matrimonios sin hijos -en especial cuando no desean tener hijos- muestran mayor ajuste y satisfacción entre la pareja. No en vano el énfasis en la familia y un número de hijos elevado, como fuente primaria de gratificación emocional está relacionado - al menos en Estados Unidos- con mayor grado de alienación social, en cuyo caso la paternidad actúa como fuente de seguridad e identificación. Alguna indicación, aunque indirecta, puede señalarse para España respecto a la dimensión de la familia que está en razón inversa a las posibilidades de obtener satisfacciones en áreas diferentes a los hijos. Comparando las Encuestas de Juventudes de 1960 y 1968 , por ejemplo, se observa que el ideal familiar de vida disminuye a medida que el nivel de instrucción y el status ocupacional aumenta ${ }^{43}$.

Academic Press, 1978, 360 pp.; E. B. LuCKey y J. K. BaIN, "Children: a factor in marital satisfaction", J.M.F., vol. 32, núm. 1, 1970, pp. 43-45. También en Estados Unidos se encuentra extendida la creencia en que tener hijos favorece la armonía y relación de la pareja; $K$. S. Thompson, "A comparison of black and white adolescent's beliefs about having children", J.M.F., vol. 42, núm. 1, 1980, pp. 133-140.

${ }^{42} \mathrm{~S}$. Hewert, The family and the handicapped child, Chicago, Aldine Publishing, 1970, especialmente cap. $4 .^{\circ}$, y el artículo de R. MCAllister y otros en J.M.F., vol. 35, núm, 1, 1973, pp. 93 y ss. Que sepamos esta cuestión no ha sido investigada en España, aunque algunas referencias pueden verse en A. Bravo SiERra, "La repercusión del hijo deficiente mental en el trabajo de la mujer y en las tareas familiares", en VARIOS AUTORES, El trabajo de la mujer con responsabilidades familiares, ed. Ministerio de Trabajo, 1978, pp. 313-321.

${ }^{13}$ Datos comparativos de estas encuestas en J. González Anleo, "Ideal de la juventud española", Revista Instituto Juventud, núm. 24, 1969, pp. 45 y ss.; sobre la tasa de divorcios según número de hijos, Bumpass y SweEr, op. cit., p. 758, y B. Thornes y J. Collard, Who divorces?, Londres, Routledge and Kegan Paul, 1979, capitulo $7 .^{\circ}$; las relaciones entre natalidad y alienación en NEAL, A. G., y Groat, H. T., "Alienation correlates of Catholic fertility", A.J. of S., vol. 76, núm. 3, 1970, pp. 460-473, y L. y A. DAY, "Family size in industrial countries: an inquiry into social cultural determinants of levels of childbearing", J.M.F., volumen 31, núm. 2, 1969; la vinculación entre ausencia voluntaria de hijos y ajuste matrimonial, en S. K. HouseKNECHT, "Childlessness and marital adjustment", J.M.F., vol. 41, núm. 2, 1979, pp. 259-267, y en H. FeldMaN, "A comparison of intentional parents and intentionally childless couples", J.M.F., vol. 43, núm. 3 , 
Otras tendencias ya mencionadas también han sido examinadas respecto a España, aunque no, todavía, en análisis de matrimonios divorciados. Las discrepancias y tensiones más frecuentes entre la pareja provienen de temas económicos o de los hijos (que guardan entre sí, como vimos, estrecha relación). Su llegada puede traer consigo la salida al exterior de divergencias hasta entonces latentes, como en materia religiosa, educativa, social, ideológica, etc. La propia naturaleza total, y no segmentaria, de la relación entre padres e hijos multiplica las áreas de discrepancia potencial de la pareja. $Y$ en un terreno donde no resulta fácil armonizar convicciones, ni lograr equilibrios, por el mismo alcance que el sistema cultural otorga a la crianza de los hijos.

En todo caso, ya el Segundo Informe Foessa de 1970 reveló que los hijos eran la principal fuente de discrepancias de la pareja. Así, el número de hijos que hay que tener, los gastos de la casa y el educar a los hijos constituyeron los más frecuentes motivos de desacuerdo (de un total de 14) de las amas de casa en la semana anterior a la entrevista. La misma tendencia se aprecia en el ya mencionado estudio, de 1976, para el Instituto de la Opinión Pública. Aquí la mitad de los entrevistados responden que son muchos los cambios que la llegada de los hijos ocasionan en las relaciones de la pareja. Esta opción aparece sobre todo entre quienes declaran más práctica religiosa, más ingresos, mayor nivel educativo y clase social subjetiva más elevada. También entre los entrevistados menores de 35 años. Quizá porque buena parte de los mismos tengan hijos de corta edad y estén viviendo, por consiguiente, los cambios que producen en la relación de la pareja. Mientras que, pasada ya esa fase, entre los entrevistados con más edad pueden quedar desdibujados -o incluso idealizados- sus efectos. $\mathrm{O}$ al menos atribuir los cambios a circunstancias ajenas a los propios hijos. A los entrevistados que respondían que los hijos ocasionaban muchos o pocos cambios (el 60 por 100 en total), se les preguntó a continuación en qué consistían dichos cambios. Y la referencia más mencionada es crítica: para el 31 por 100 crean más problemas en el matrimonio. Interesaba también verificar la posible incidencia desigual originada según el sexo de los hijos. Por ello se les preguntó «en general quién cree usted que ocasiona más problemas y preocupaciones a los padres, ¿los hijos o las hijas?», con los siguientes porcentajes (se incluye también «por igual», pues se advirtió a los entrevistadores que lo anotaran en los casos que así les respondieran):

1981, pp. 593-601. De todas maneras es reducida la proporción de la población que desea no tener hijos, aunque esta actitud es más frecuente entre las mujeres, quizá porque en ellas recae la crianza; J. BLAKE, "Is zero preferred? American attitudes toward childlessness in the 1970's", J.M.F., vol. 41, núm. 2, 1979, pp. 245258; sobre el papel de los hijos como mantenedores, que no de la armonía, del matrimonio, A. Bоотн у L. WhITE, "Thinking about divorce", J.M.F., vol. 42, número 3, 1980, pp. 605-617. 


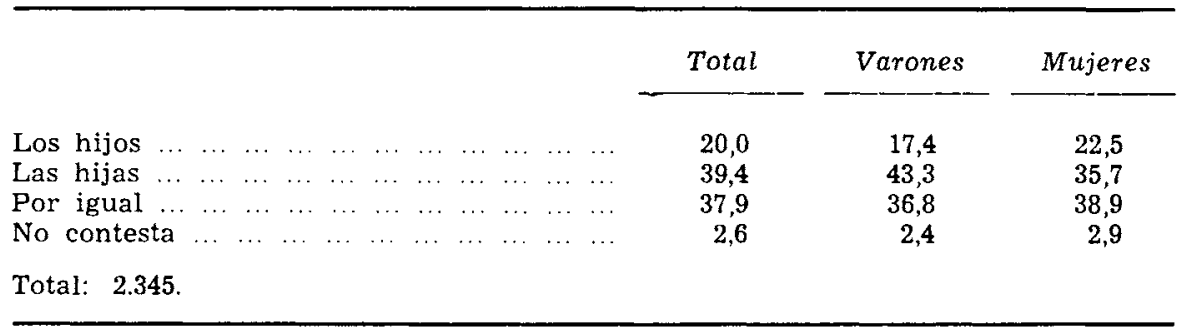

Como se ve, las hijas son mencionadas por el doble de entrevistados que los hijos. Y la variable más discriminatoria es el sexo. Mientras los varones en primer lugar mencionan a las hijas, las mujeres opinan que crean problemas por igual. No resulta posible extraer una interpretación concluyente de estos resultados. Me inclino a pensar que en buena parte reflejan los prejuicios antifeministas, tan extendidos en la sociedad española. Pero otras apreciaciones son posibles. Los cambiantes contenidos del rol de la mujer o las mayores presiones hacia la sumisión y obediencia - y, en general, el más estricto control de su comportamiento- puede desencadenar a la postre mayor frecuencia de disputas generacionales y matrimoniales. No puede excluirse, por ejemplo, que las pautas de socialización diferencial de la mujer ocasionen en la fase de emancipación — por mitigada que seamás roces y conflictos que la de los varones con la red familiar. Esta es la conocida tesis de Komarovsky ${ }^{44}$; el tipo de socialización y dependencia familiar que se impone a la mujer dificulta su transición para el desempeño de roles adultos y favorece la aparición de tensiones con la familia de orientación.

Tampoco parece que se esté produciendo una evolución hacia menores dosis de conflictos o discusiones en el matrimonio a causa de los hijos. Buena prueba de ello es la investigación, de 1980, realizada por Salustiano del Campo y Manuel Navarro ${ }^{45}$. La educación o el trato dado a los hijos, en efecto, para los varones como las mujeres entrevistadas, es el tema de discusión más frecuente entre el matrimonio y a continuación aparece «por cuestiones de dinero», lo cual pudiera guardar alguna relación también con los hijos que son, además, el tema de conversación más frecuente de la pareja.

La incidencia de la educación de los hijos en las tensiones matrimoniales, me parece que está sufriendo un espectacular incremento en la última década. Aun sin monografías al respecto, me parece una hipótesis muy plausible y de obligada mención aquí. Es un hecho conocido la espectacular explosión de demandas de enseñanza para los hijos, que trajo consigo la Ley

4* M. Komarovsky, "Functional analysis of sex roles", en Eisenstadt (ed.), Comparative Social Problems, 1964, pp. 202 y ss.

${ }^{45} \mathrm{~S}$. del Campo y M. Navarro, Análisis sociológico de la familia española, Ministerio de Cultura, 1982, pp. 118-122. 
General de Educación en el umbral de la década de los setenta. Demanda de educación ocasionada por las crecientes esperanzas depositadas en ella como instrumento de movilidad social y cultural. Estas aspiraciones desencadenaron, además, crecientes gastos de las economías familiares, por la insuficiencia de centros públicos, dispuestas a realizar esfuerzos desproporcionados para dar estudios a sus hijos. La enseñanza y rendimiento educativo de los hijos se ha convertido en una de los acontecimientos más decisivos, también, para los padres. La insistencia en la educación por los padres - tal vez proyectando sus propias aspiraciones frustradas- se convie en causa de conflictos entre padres e hijos $\mathrm{y}$, a mi entender, con suma frecuencia también entre la pareja; en especial en los casos de fracaso escolar. Los cada día más frecuentes casos de suicidios infantiles o tentativas ${ }^{46}$ constituye un indicador de la obsesión paterna por la productividad escolar de sus hijos que no puede carecer de consecuencias en la propia relación matrimonial.

Los aspectos que he venido examinando me parece que imponen, cuanto menos, dos conclusiones con particular urgencia respecto a la sociedad española. En primer lugar, la necesidad de incrementar sustancialmente la atención prestada por los científicos sociales, de todas las especialidades, a la infancia. Son demasiadas las incógnitas y lagunas existentes respecto a un grupo social en tantas ocasiones catalogado como decisivo para el futuro de nuestra propia sociedad; frase habitualmente empleada para tapar nuestra ignorancia y que denota lo poco que, en realidad, nos importa la infancia en cuanto tal, sin sesgos adultos. Lo decisivo pues no es el devenir, sino el propio presente de la vida de todas las generaciones durante su infancia. $Y$ entiendo que su propia felicidad, bienestar y status social podrían resultar beneficiados con mayor atención que hasta el presente por parte de los estudiosos sobre esta fase de la vida.

En segundo lugar, es preciso instaurar $-y$ empleo este verbo pues, hasta ahora, puede darse por inexistente - una decidida política oficial en favor de la infancia. No entiendo, por ejemplo, que se catalogue como progreso social el que un porcentaje de cada gran obra pública se dedique a obras culturales y, simultáneamente, se realice sin para nada tener presente los intereses de los niños. Moldeamos así el espacio de espaldas y en contra de los intereses del desenvolvimiento de la infancia. Casos semejantes pudieran citarse en abundancia. Pero no son del caso. Trato, por el contrario, de subrayar la necesidad de una política vigorosa en defensa de la infancia,

${ }^{46}$ P. Alcobendas, "El suicidio infantil y juvenil en España", Rev. Instituto Juventud, núm. 28, 1970; también las breves referencias al tema en J. M. de Miguel, El ritmo de la vida social, Tecnos, 1973, 4. parte. Periódicamente aparece en la prensa información al respecto; véase el reportaje en El País, 6 julio 1977, p. 44. 
que incida en todos los ámbitos de la convivencia. Con repercusión en la política del gasto público sin duda; pero mucho más de fondo que las meras acciones económicas. Lo que no resulta admisible es que en una época, como la actual, las reivindicaciones y demandas de los distintos sectores sociales den como resultado la postergación indefinida de quienes no tienen voz.

Carecen en efecto de voz, en gran medida porque los adultos se la secuestramos y así los etiquetamos y definimos: «Es posible hablar con los niños -escribió Adorno ${ }^{47}$ - mucho más madura y seriamente que lo que los adultos para ratificarse por ese medio a sí mismos su propia madurez, están dispuestos a reconocer.» Bueno será comenzar por restituirles, pues, la palabra. Y para ello nada mejor que evocar la lección recibida por un antropólogo estudiando una sociedad denominada, a veces despectivamente, primitiva. En el curso de su trabajo, el investigador preguntó a una madre si su hijo hablaba; le respondió en efecto que sí, e inmediatamente -cualquiera de nosotros- quedó confundido ante los sonidos «sin sentido» emitidos por el niño. Sabiamente, la madre le puntualizó que el niño hablaba, pero que era ella quien no entendía lo que él decía. Ciertamente toda una advertencia a seguir.

${ }^{47}$ T. Adorno, Consignas, Buenos Aires, ed. Amorrortu, 1973, p. 77. 